\title{
(Vi)ver mais: a realidade silenciada pela dependência - projeto de intervenção comunitária
}

\section{Live further: a silenced reality by dependency - community intervention project}

\author{
Elisabete Martins*, Clara Costa Oliveira*, Teresa Bandeira**, Alexandra Nobre* \\ * Universidade do Minho, ${ }^{* *}$ Comunidade Terapêutica Viver Mais
}

\begin{abstract}
Resumo
A adição afeta um grupo díspar de indivíduos que tendem a ser desacreditados. Rejeitando esta visão, desenvolveu-se um projeto comunitário de educação não-formal de adultos. $\mathrm{O}$ público-alvo da intervenção foi um grupo de residentes de uma comunidade em processo de tratamento por problemas de adição e/ou distúrbios cmportamentais. Esta investigação centrou-se na transformação do quotidiano e desenvolvimento pessoal/social dos utentes, por forma a melhorar o seu bem-estar. Para esse efeito, implementaram-se atividades agrupadas por áreas temáticas. O projeto alerta para a importância de intervenções similares. É necessário conhecer o contexto real e as pessoas para uma intervenção eficaz e valorizada.

Palavras-chave: educação não-formal, toxicodependência, intervenção comunitária, adição
\end{abstract}

\begin{abstract}
Addiction affects a diverse group of individuals that are usually impeached by society. Refusing this view, we developed a community project in the context of adult non-formal education. The target population was a group of residents of a community, undergoing a therapeutic process due to addiction and/or behavior disorders. This research focused on daily life transformations and personal/social development of participants, in order to improve their well-being. For this purpose, we implemented a set of thematic activities. Our project draws attention to the importance of similar interventions. For an effective and valued intervention, knowing the real context and the people is needed.

Keywords: non-formal education, drug addiction, community intevention, addiction
\end{abstract}

Ao perspetivarmos a "educação como um processo largo e multiforme" (Canário, 2000, p.11), equiparado ao decurso de vida de cada indivíduo, denotámos que a vertente educativa destinada ao público em idade adulta sempre existiu. No entanto, a partir da segunda metade do século $\mathrm{XX}$, esta deixa de estar confinada a um conjunto restrito de minorias socioprofissionais $\mathrm{e}$ socioculturais e estende-se à totalidade dos indivíduos (Antunes, 2001). A educação de adultos destina-se tanto a educandos como educadores, já que para os primeiros há uma necessidade e para os segundos uma responsabilidade na melhoria dos processos de desenvolvimento humano (Dias, 2009).
A revalorização do valor estratégico dos investimentos em educação e as práticas educativas e formativas não podem circunscrever-se a momentos pontuais da vida de cada pessoa. Pelo contrário, devem retratar um processo de desenvolvimento que ocorre ao longo da sua existência, sendo a partir deste prisma abarcada pelo conceito de educação ao longo da vida (Antunes, 2008). Segundo Dias (2009) a educação ao longo da vida é "um projecto global que visa não só reestruturar o sistema educativo existente, mas também desenvolver todo o potencial de formação fora do sistema educativo" (pp. 214-215). O presente projeto assenta nos conceitos da área educativa, utilizando-os, de uma forma fluída, num espetro comunitário.

A intervenção comunitária caracteriza-se pela aposta no desenvolvimento de pessoas e comunidades, constituindo projetos, cuja finalidade é a transformação progressiva de formas de vida mais desfavorecidas (Antunes, 2007). Por isso, esta forma de intervenção funciona como uma conduta que se destina à promoção de uma melhoria do nível de vida das pessoas. Esta via de atuação traduz o conceito de educação comunitária definida como um processo global e sequencial de desenvolvimento das comunidades humanas, a partir da interacção dos processos de educação ao longo da vida de cada um dos seus membros (Dias, 2009).

A globalidade de métodos e procedimentos de índole comunitária são determinados pelo envolvimento da população que vai, gradualmente, arrogando a sua centralidade e pela correta e adequada utilização, por parte dos distintos agentes envolvidos, dos recursos de que dispõem (Carrasco, 1997). As condições essenciais para a prossecução de um projeto de intervenção giram em volta do conhecimento aprofundado do contexto para onde se direciona a nossa ação, englobando esse conhecimento as condições sociais do grupo e uma compreensão integral dos recursos disponíveis (Carrasco, 1997).

A comunidade deve sempre ser entendida como um todo e não como pequenas frações ou setores de indivíduos, e a totalidade de objetivos e metas traçadas devem atender às particularidades desse todo (Marchioni, 1999). Não obstante, convém estar consciente de que nem todas a pessoas participam da mesma forma ou mesmo se envolvem. Nesse sentido, os 
técnicos que integram as comunidades permanentemente não podem ser descurados aquando da intervenção. Eles devem coordenar-se com todos os intervenientes em torno de um objetivo comum: um trabalho com o grupo e não para o grupo (Marchioni, 1999).

O ponto de partida de um projeto comunitário deve ser impulsionado através da iniciativa de um dos agentes envolvidos que deve garantir os recursos para o sucesso do projeto. No entanto, convém referir que a dinâmica do processo integra momentos de avanços e recuos, momentos pacíficos e de conflito, êxitos e fracassos, como em todo o processo humano (Marchioni, 1999).

Em particular, as comunidades terapêuticas devem seguir uma lógica comunitária e educativa. Estes contextos que se destinam ao internamento e acompanhamento de pessoas com problemas de dependências e/ou comportamentos desviantes não devem circunscrever a sua prática ao tratamento de sintomas provocados pela privação aguda da substância em questão (Rosa, Gomes, \& Carvalho, 2000). Deverão, por isso, atuar de forma a compreender a pessoa na sua globalidade, a sua forma de ser, de estar, de sentir e de gerir a sua sobrevivência, ajudando assim a promover as mudanças que se entendam necessárias. Um processo de tratamento eficaz tem de incluir as dimensões envolvidas e afetadas pela dependência - a dimensão física, a dimensão psíquica e a dimensão social (Rosa et al., 2000).

A comunidade terapêutica alvo da presente investigação procura atuar nas dimensões supracitadas, principalmente em dois tipos de dependência: toxicodependência e alcoolismo. A primeira define-se como um estado mental que requer o uso periódico ou contínuo de uma droga com o fim de criar um prazer ou anular uma tensão e, simultaneamente, como uma exigência do organismo para conservar um eventual equilíbrio que exige o aporte regular de um produto químico do exterior" (Rosa et al., 2000). A segunda é descrita como sendo "o protótipo de uma toxicodependência", na medida em que o consumo enraizado de álcool " [...] conduz a dependência tanto física como psicológica e a importantes perturbações orgânicas" (Morel, Hervé, \& Fontaine, 1998, p.25).

Este trabalho centrou-se no modo como pode ser transformado o quotidiano dos residentes dentro da instituição de recuperação aditiva, por forma a melhorar o seu bem-estar. Para esse efeito, começámos por elaborar um diagnóstico com a população e técnicos da instituição de forma a identificar os interesses e necessidades do público-alvo. Com base nesse diagnóstico desenharam-se atividades participadas envolvendo conceito de ciência e de empoderamento social. A intervenção visou a promoção e consequente valorização do desenvolvimento pessoal e social dos utentes, pretendendo culminar na aproximação desta comunidade a uma vida participativa em sociedade.

\section{Método}

\section{Fundamentação metodológica}

Nesta investigação optou-se por uma metodologia de investigação-ação participativa, de cariz qualitativo, por forma a manter a coerência com os objetivos estipulados. Partiu-se do pressuposto de que o mundo social é construído por significados, sendo esses significados investigados na interação com as pessoas nos seus próprios contextos (Moreira, 2007). O conhecimento é produzido em conjunto por investigadores e participantes com vista à resolução de problemas concretos vividos por estes últimos (Guerra, 2002).

\section{Participantes}

Os participantes desta investigação são trinta e oito utentes de uma comunidade terapêutica, com idades compreendidas entre os 21 e os 60 anos de idade. Esta comunidade dedica-se ao tratamento de pessoas que sofrem de alcoolismo, dependência química e distúrbios alimentares e/ ou comportamentais. As habilitações académicas dos residentes variam entre o $1^{\circ}$ ciclo e o mestrado. Quanto à situação profissional contam-se vinte desempregados, quinze empregados, dois estudantes e um reformado.

É importante referir que os elementos do público-alvo flutuaram ao longo da intervenção, devido à conclusão, admissão e/ou abandono do ciclo de tratamento.

\section{Instrumentos}

Relativamente aos instrumentos destacam-se algumas técnicas de investigação/intervenção, as quais possibilitam orientar e planear as atividades de trabalho (Pardal \& Lopes, 2011). Seguidamente, caracterizam-se as técnicas principais.

Inquérito por questionário. Conjunto de questões sobre o tema de pesquisa, sequencialmente dispostas em itens, com objetivo de suscitar opiniões ou informações aos inquiridos (Chizzotti, 2000).

Observação participante. Recolha de dados a partir da assunção de uma postura participante pelo investigador. Esta técnica permite a obtenção de informações fidedignas sobre a realidade, a partir do interior, e o registo de factos imediatamente após a sua ocorrência (Pardal \& Lopes, 2011).

Diário de bordo. Relato escrito que organiza o material recolhido ao longo do dia, permitindo ao investigador que reflita sobre as suas observações e faça o ponto da situação (Moreira, 2007).

Dinâmicas de grupo. Estudo das dinâmicas de pequenos grupos, ou seja, dos fenómenos psicossociais característicos do grupo como tal (Minicucci, 1992). São realizadas com o intuito de obter conhecimento dos princípios do funcionamento grupal e de promover mudanças de comportamento.

Brainstorming. Interação em pequeno grupo, concebida para incentivar a livre promoção de ideias sem restrições nem limitações. É uma técnica de promoção da criatividade (Miniccuci, 1992).

Animação lúdica. Prática de integração da componente teórica presente nas atividades com técnicas lúdicas de animação, com vista a fomentar a motivação e envolvimento dos participantes.

\section{Procedimento}

O processo de desenvolvimento da presente investigação ocorreu em três fases principais. Primeiro o 
dignóstico inicial teve como intuito identificar as principais necessidades e interesses do público-alvo. Com recurso a questionários e levantamentos informais realizados com toda a comunidade, juntamente com reflexões da própria invetsigadora, através de anotações em contexto, esboçou-se uma linha de intervenção, na qual a participação dos utentes era a prioridade.

Partindo dos dados recolhidos em fase antecedente procedeu-se à criação de um conjunto de atividades, agrupadas em sete àreas temáticas diferenciadas, cuja concretização visou essencialmente promover a adoção de um estilo de vida saudável, a melhoria de competências de comunicação e expressão e o interesse pelo mundo científico. Em suma, uma aproximação à vida em sociedade.

Por fim, a avaliação do projeto ocorreu por duas vias distintas. Tendo em consideração que a grande maioria dos utentes não participou de forma continuada no projeto (admissão, abandono e/ou término do tratamento) surgiu a necessidade de avaliar cada atividade à medida que as mesmas iam sendo realizadas. No final da implementação do projeto procedeu-se a uma avaliação global. Esta foi sustentada quer pelos dados recolhidos nos inquéritos de avaliação, quer pela integração crítica das perspetivas e comportamentos dos participantes, ao longo de todo este processo.

\section{Resultados}

A intervenção na comunidade onde se desenvolveu este projeto resultou na realização das atividades temáticas, com participação direta dos utentes, suportadas nas técnicas de intervenção/investigação acima mencionadas. A somar, procurou-se investigar os impactos concretos das dinamizações, através da observação da reação dos utentes às atividades e das mudanças nos seus comportamentos e formas de pensar.

\section{Sociedade atual}

Esta área de interesse englobou um conjunto de sete temáticas - política; eutanásia, distanásia e testamento vital; interrupção voluntária e involuntária da gravidez; terrorismo; violência doméstica, escolar e outras; homossexualidade e adoção por casais homossexuais; e desigualdades de género- que têm, de algum modo, influenciado o quotidiano da sociedade na qual estamos inseridos. Inicialmente fez-se o levantamento de um conjunto de notícias da atualidade, contendo opiniões distintas. Em fase posterior realizou-se um brainstorming com intuito de compreender a opinião de cada utente, e a partir do qual se gerava uma discussão grupal.

A dinamização obteve um nível de satisfação elevado, contribuindo, na opinião dos participantes, para a promoção da reflexão e fomento de experiências. No entender dos utentes a atividade também foi útil para o desenvolvimento pessoal/profissional.

\section{Responsabilização social}

Visando elucidar os utentes em relação aos direitos e deveres civis, foi realizado um brainstorming no qual cada elemento devia enunciar os direitos e os deveres que conhecia. Este foi o ponto de partida para uma dinâmica de grupo com dois momentos. Primeiro os participantes deviam identificar quais os direitos e deveres que já haviam desrespeitado e depois, enunciar aqueles que lhes que foram, segundo a sua visão, negados. Em ambos os momentos abriu-se espaço para discussão e validação de experiências partilhadas entre os residentes.

A dinamização obteve um nível de satisfação elevado, contribuindo, na opinião dos participantes, para a promoção da reflexão e fomento de experiências. Houve também reconhecimento da utilidade pessoal/profissional desta atividade, para os participantes.

\section{A ciência da nossa vida}

Através de sessões de sensibilização sobre as diferentes drogas (tabaco, álcool, cocaína, heroína e cannabis), de experiências de fermentação alcoólica e medição/ recriação do volume de álcool de diferentes bebidas, da construção de um "cigarro gigante" ilustrando a sua composição química principal estimulou-se a discussão sobre algumas das particularidades destas substâncias como sejam a sua composição química, a origem, a sua incidência nas bebidas e alguns dos principais efeitos no organismo. A acrescentar, realizaram-se também tarefas práticas de promoção de um estilo de vida mais saudável, através da plantação de uma mini horta biológica, do cálculo do valor energético dos alimentos consumidos pelo público-alvo e da exemplificação de atividades físicas para desgaste da energia ingerida associada aos alimentos.

Estas atividades tinham como finalidade, por um lado aproximar os utentes do mundo e conhecimento de ciência e, por outro, promover a adoção de um estilo de vida mais saudável, através da alteração de hábitos enraizados e do contacto com a outra realidade das suas dependências.

As atividades obtiveram um grande nível de satisfação. Os participantes revelaram que a dinamização promoveu reflexão e consideraram existir um grande impacto desta na alteração dos seus comportamentos e hábitos.

\section{Educação e emprego}

Dada a elevada taxa de desemprego patente no grupo de utentes da comunidade terapêutica em causa surgiu a necessidade de abordar temáticas de cariz socioprofissional, nomeadamente sobre o currículo e as entrevistas de emprego. Através de exercícios de simulação contextual e de brainstorming os participantes foram colocados em contacto com o mundo do trabalho e com as exigências do mesmo. Foi-lhes pedido que refletissem criticamente sobre si próprios e que identificassem mais-valias pessoais, úteis em contextos profissionais.

Neste caso particular, as dinâmicas obtiveram um nível de satisfação e aceitação mais moderado. Os utentes afirmaram uma menor promoção da reflexão e experiências, limitando-se apenas a uma descrição das suas situações individuais. Ainda assim, reconheceram alguma utilidade para o seu desenvolvimento pessoal/profissional. 


\section{Educação para a saúde/atividades com dimensão corporal}

Estas áreas temáticas surgem articuladas, tendo como objetivo auxiliar os utentes em fase de maior instabilidade e estagnação. Constituindo a ansiedade um dos principais entraves ao processo de tratamento foram compiladas um conjunto de atividades com objetivo de dotar os utentes de competências que lhes permitissem dar resposta a situações de maior tensão, como são exemplo a prática do ioga, o relaxamento através da música e a terapia da arte - pintura.

Os participantes revelaram-se muito satisfeitos com estas atividades, apesar de terem demonstrado alguma resistência inicial. Além disto, estas atividades não promoveram o desenvolvimento profissional, nem a reflexão sobre ideias. No entanto, permitiram aos utentes a aquisição de recursos de coping em situações de instabilidade e ansiedade, sendo esse o objetivo principal.

\section{Relacionamento interpessoal}

Esta área temática pretendeu aumentar a capacidade de relacionamento interpessoal, a qual tende a ser pautada pela inadequação da comunicação e pelo desconhecimento do seu grupo de pares. Através de brainstorming, simulação em contexto e dinâmicas de auto e hetero conhecimento, os residentes colocaram-se no papel do outro e identificaram comportamentos inadequados.

A aceitação da atividade foi elevada dado o desconhecimento dos utentes sobre as suas próprias competências relacionais. A reflexão provocada foi bastante relevante, contribuindo de forma direta para a alteração de comportamentos e, consequentemente para o desenvolvimento pessoal.

\section{Discussão}

Partindo das fases de investigação e de intervenção procurámos perceber de que modo um projeto de educação de adultos, de âmbito comunitário, pode ser vantajoso em contexto de tratamento de dependências e/ou distúrbios comportamentais. O projeto pretendeu também verificar qual o impacto das diversas dinâmicas concretizadas no quotidiano dos utentes em fase de internamento.

A diversidade das atividades implementadas durante a intervenção permitiu dinamizar as rotinas diárias dos utentes, que se revelam por norma monótonas, sendo o seu desenvolvimento circular. No nosso entender, é importante introduzir mudanças nos ciclos diários para gerar aumentos de motivação para a participação, evitando ao mesmo tempo momentos de estagnação no progresso terapêutico, algumas vezes associado a estados de humor depressivos (ver Del Porto, 1999).

Mais ainda, a implementação das atividades no contexto real permitiu compreender que as vertentes afetas ao processo de desabituação empreendidas nesta comunidade são demasiado restritas. Há uma grande preocupação com a componente psicológica e física da dependência, sendo todas as sessões de dinamização voltadas para reflexão e reformulação das cognições sobre essa temática. Por essa razão é importante atender à dimensão social da intervenção com vista à reinserção, aumento da autonomia e consolidação do tratamento (Rosa et al., 2000). O presente trabalho, aliado às atividades implementadas, tentou fornecer recursos sociais (e.g. técnicas de comunicação) fundamentais para fortalecer as probabilidades de sucesso do processo terapêutico global (Coelho, 2016).

É necessário reforçar que o projeto tratado neste artigo contou como pedra angular para o seu sucesso, o envolvimento dos participantes nas dinamizações. Quando os utentes tratam como suas as atividades e tarefas a si atribuídas, aumentam o seu empenho o que em consequência potencia a reflexão e integração das aptidões adquiridas como recursos relevantes para uma vida em sociedade. No seio da educação de adultos, onde estes são os próprios agentes, a recetividade a novas experiências e conhecimentos, associada ao aproveitamento das vivências, pode consolidar o processo de aprendizagem (Pereira, 2013).

É neste sentido que o trabalho se revelou bem-sucedido. Pese embora as dificuldades e constrangimentos existentes em qualquer empreendimento científico, acreditamos que o projeto contribuiu para melhorar o bem-estar dos utentes e os tornou mais conscientes do longo processo de reinserção social (Silva, 2011).

Quanto às limitações, destaca-se a grande variação do número de utentes, o que impossibilitou uma participação contínua no projeto. Além disso, as diferenças existentes no grupo de participantes (idade e habilitações académicas) dificultam o planeamento de atividades, porque este tem de dar resposta a uma grande variedade de interesses e diferentes níveis de participação (cf. Marchioni, 1999). Por fim, é necessário ter em conta que a flutuação dos participantes nas atividades tem repercussões na motivação para continuar nos restantes residentes, não sendo fácil lidar com a frustração ou sensação de perda de pessoas próximas que desistiram ou concluíram o processo terapêutico.

O presente artigo chama a atenção para a importância do desenvolvimento de intervenções similares, pois estas permitem a diversificação da realidade destas comunidades e a consciencialização do público-alvo da centralidade da sua participação na recuperação e aproximação à vida em sociedade.

\section{Referências}

Antunes, M. C. P. (2001). Teoria e prática pedagógica. Lisboa: Instituto Piaget.

Antunes, M. C. P. (2007). Educação de adultos e intervenção comunitária II. Coimbra: Edições Almedina S.A.

Antunes, M. C. P. (2008). Educação, saúde e desenvolvimento. Coimbra: Edições Almedina S.A.

Canário, R. (2000). Educação de adultos: Um campo e uma problemática. Lisboa: Educa.

Carrasco, J. G. (1997). Educación de adultos. Barcelona: Editorial Ariel S.A.

Chizzotti, A. (2000). Pesquisa em ciências humanas e sociais. São Paulo: Cortez. 
Coelho, S. C. C. (2016). (Re)aprender a ser e a conhecer: Desenvolvimento de competências com toxicodependentes. Dissertação de mestrado em Educação de Adultos e Intervenção Comunitária. Universidade do Minho, Braga, Portugal.

Del Porto, J. A. (1999). Conceito e diagnóstico. Revista Brasileira de Psiquiatria, 21(1),6-11. https://dx.doi.org/10.1590/S1516-4446199900050000 3

Dias, J. R. (2009). Educação - o caminho da nova humanidade: Das coisas às pessoas e aos valores. Porto: Papiro Editora.

Guerra, I. C. (2002). Fundamentos e processos de uma sociologia de acção - o planeamento em ciências sociais ( $2^{\mathrm{a}}$ edição). Cascais: Principia, Publicações Universitárias e Científicas.

Marchioni, M. (1999). Comunidade, participación y desarrollo: Teoría y metodología de la intervención comunitaria. Madrid: Editorial Popular S.A.

Minicucci, A. (1992). Técnicas do trabalho de grupo (2a Edição). São Paulo: Editora Atlas S.A.

Moreira, C. D. (2007). Teorias e práticas de investigação. Lisboa: Instituto Superior de Ciências Sociais e Políticas.

Morel, A., Hervé, F., \& Fontaine, B. (1998). Cuidados ao toxicodependente ( $1^{\text {a }}$ Edição). Lisboa: Climepsi Editores.

Pardal, L., \& Lopes, E. S. (2011). Métodos e técnicas de investigação social. Porto: Areal Editores.

Pereira, A. (2013). Ação social solidária: Caminhos de educação de adultos e intervenção comunitária. Dissertação de mestrado em Educação de Adultos e Intervenção Comunitária, Universidade do Minho, Braga, Portugal.

https://repositorium.sdum.uminho.pt/bitstream/1822/29 308/1/Relat\%C3\%B3rio\%20de\%20est\%C3\%A1gio\% 20Andreia.pdf

Rosa, A., Gomes, J., \& Carvalho, M. (2000). Toxicodependência: Arte de cuidar. Coimbra: Formasau.

Silva, D. (2011). A mediação socioeducativa como campo de intervenção na toxicodependência. Dissertação de mestrado em Mediação Educacional e Supervisão da Formação, Universidade do Minho, Braga, Portugal.

https://repositorium.sdum.uminho.pt/bitstream/1822/19 254/1/Daniela\%20Alexandra\%20Dinis\%20da\%20Sil va.pdf

\section{Agradecimentos}

Elisabete Martins agradece a generosidade e abertura da Comunidade Terapêutica Viver Mais de Braga, que tornou possível a prossecução deste projeto de investigação/intervenção.

\section{Notas}

Dependências são estados com dupla vertente: psíquica e física. Resultam da interação entre a pessoa e uma substância, caracterizando-se por alterações comportamento e outras reacções que envolvem sempre uma compulsão a tomar o produto de modo contínuo (Rosa et al., 2000). 